\title{
Optimal strategies in political elections
}

\author{
D. Lesmono* $\quad$ E. J. Tonkes ${ }^{\dagger}$
}

(Received 21 October 2004, revised 9 June 2005)

\begin{abstract}
In the Majoritarian Parliamentary System, the government has a constitutional right to call an early election. This right provides the government a control to achieve its objective to remain in power for as long as possible. We model the early election problem mathematically using opinion polls data as a stochastic process to proxy the government's probability of re-election. These data measure the difference in popularity between the government and the opposition. We fit a mean reverting Stochastic Differential Equation to describe the behaviour of the process and consider the possibility for the government to use other control tools, which are termed 'boosts' to induce shocks to the opinion polls by making timely policy announcements or economic actions. These actions improve the government's popularity and have some impact upon the early-election exercise boundary.
\end{abstract}

*Department of Mathematics and Advanced Computational Modelling Centre, University of Queensland, Brisbane, Australia, mailto:dlesmono@maths.uq.edu .au; and Department of Mathematics, Parahyangan Catholic University, Bandung, INDONESIA. mailto: jdharma@home. unpar.ac.id

${ }^{\dagger}$ Department of Mathematics, University of Queensland, Brisbane, Australia.

See http://anziamj.austms.org.au/V46/CTAC2004/Lesm for this article, (C) Austral. Mathematical Soc. 2005. Published August 8, 2005. ISSN 1446-8735 


\section{Contents}

1 Introduction

C765

2 The model

2.1 Notation and formulation . . . . . . . . . . C C768

2.2 Transition probabilities and parameter fitting . . . . . C C771

3 Results

C772

3.1 Expected remaining life . . . . . . . . . . . . . C773

3.2 Exercise boundaries . . . . . . . . . . . . . . . . C C773

3.2.1 Call exercise boundaries . . . . . . . . . . . C777

3.2.2 Boost exercise boundaries . . . . . . . . . . C777

4 Extension

C779

5 Conclusions and further research

C782

References

C784

\section{Introduction}

In the Majoritarian Parliamentary System, the government has a constitutional right to call an early election, which can give the government an advantage to be in power as long as possible if they use it wisely. In Australia, where there is a maximum period of three years between elections, the Australian Constitution and Commonwealth Electoral Act gives this right to the Federal Government subject to the Governor General's approval.

When an election is called, indicative factors such as an aggregation of expert opinion or bookmakers' dividends are available to predict the answer of the question "which party will next be in power". We chose to use Mor- 
gan polls to measure the voting intentions of the public and to derive the probability of a government being returned to power.

Opinion polls do not necessarily reflect the outcomes of an election [5]. Noncompulsory voting, sampling and response errors, and importantly the effect of an exaggerated majority (due to the common practice of regional representation) all impact on the probability of re-election. Probabilistic methods based on historical precedents encompass these situations in our model.

Voting in Australian Federal Election follows a Majoritarian Alternative Vote system [3]. Voters register preferences for each candidate and preferences are iteratively distributed until one party achieves the majority of preferences. We concern ourselves with rules for the Australian Federal House of Representatives and use the associated historical electoral data.

We assume that governments have some control mechanisms over the polls. Some actions by the government seem to affect the polls; for example, policy announcement of the budget, tax breaks, health and education. Also, it is common practice for governments to restrict spending early in their term and release much more expenditure later in the term, presumably to please the public and 'buy' votes [2]. Grant [4] discusses the intentional decision made by government regarding policy advertising which is presumably aimed at improving the government's popularity.

Balke [1] modelled election timing as an optimal stopping model by considering the benefits and costs for the government to call an election. His formulation arrived at solving a partial differential equation with some boundary conditions. In his model, the only control owned by the government is the option to call an election or not. We extended Balke's work in [8] by introducing lead time and used a more accurate diffusion process.

We now extend our work in [8] by allowing the government to use some control tools, which we term 'boosts', to induce shocks to the opinion polls by making timely policy announcements or economic actions. These boosts lift 
the government's popularity and we study their effect upon the early-election exercise boundary. As in [8], we use Morgan poll data for measurement of the government's and the opposition's popularity, fit a mean reverting stochastic differential equation (SDE) model to the data, and use a maximum likelihood method to estimate parameters of our model. We assume the government can only apply at most one boost at a time.

In our first model, we assume that the government is provided with a fixed number of discrete boosts for its term in office. In the extension of the model, we assume that the government is provided with a continuum of boosts, which accumulate with time and may be carried over to subsequent terms in office.

In the next section, we describe our discrete time model, notation, formulation of our problem and solution method along with transition probabilities and parameter fitting. Section 3 deals with numerical results in terms of the expected remaining life and the optimal exercise boundaries for the government's decision whether or not to use boosts and/or call an early election. In Section 4, we discuss a further extension of the model by allowing the government to determine the magnitude of boosts. We give conclusions and further research in the last section.

\section{The model}

Our variable of interest is the difference $S$ in popularity of both parties, which of course satisfies $-1<S<1$. As in [8], we model $S$ as a Markov process and fit a mean reverting SDE to describe its behaviour. We consider two main parties, Coalition (Liberal and National) and Labor parties that dominate the election process in Australia and use Morgan poll two-party preferred data (April 1993-June 2004) to measure these two parties' popularity. In general, polls are usually taken fortnightly and more frequently once an election date is announced. 
Let there be $m$ levels of popularity $S_{i}$ within the interval $(-1,1)$ and $n$ time steps dividing the maximum period of $Y$ years between elections. There is also a constant lead time $T_{L}$, the period between announcing and holding the election. According to the Australian constitution this lead time must lie between 33 and 68 days and is further restricted as elections must be held on a Saturday. In our discretised model, we set $T_{L}=k \delta t$ for some integer $k$. Later in our computation we set $m=50, T_{L}=0.12$ years (around six weeks), $n=(Y / \delta t)$ and $\delta t=0.04$ years (around two weeks). Also, we set $-0.5<S<0.5$ since in reality it is very unlikely to have the value of $S$ less than -0.5 or greater than 0.5 .

\subsection{Notation and formulation}

The state variables in our model are: $t$, time into current term; $S$, the difference in popularity; and $B$, the boost state. Define $\psi$ as the maximum possible number of time steps until the next election (taking into account whether an election has been called or not). If the election has not been called, $\psi$ is the time until the government's term is up. If the election has been called, $\psi$ is the time until the known election date. The notation we then use in developing our model follows:

- $V\left(t, S_{i}, B, \psi\right)$, the expected remaining life at time $t$ under the government's optimal strategy, when the level of popularity is $S_{i}$, the total boosts remaining are $B\left(B=0,1, \ldots, B_{\max }\right)$ and there are still at most $\psi$ periods until the election;

- $P_{i k}$, the transition probability from poll state $S_{i}$ to state $S_{k}$ over period $\delta t$ with no boost;

- $P_{i k}^{b}$, the transition probability from poll state $S_{i}$ to state $S_{k}$ over period $\delta t$ when the government has applied a boost over period $\delta t$; 
- $P\left(W \mid S_{j}\right)$, the conditional probability of winning the election from true state $S_{j}$;

- $Q_{i j}$, the conditional probability that the true state of voting intentions is $S_{i}$ given that the poll state is $S_{j}$;

- $B_{\max }$, the maximum number of boosts available at the beginning of the government's term in office.

Unless explicitly stated, we take $S_{i}$ to be the level of popularity given by the poll state at time $t$. In developing our model, we divide the political time frame into three regimes. The first regime is at the final time when $\psi=0$ (election date), the second regime is the so-called the election mode when $0<\psi \leq T_{L}$, and the third regime is the non-election mode when $\psi>T_{L}$.

In the election mode, the election date is known and the government's only decision is either to boost or not to boost. Since the objective of the government is to maximize its time in power, the decision should maximize the expected remaining life by using boosts or not using boosts.

In the non-election mode, the government has more options. The government can boost and call the election at the same time, boost but not call an election, not boost but call the election or not boost and not call the election. When there are no remaining boosts, the government can only choose whether or not to call an election.

To formulate $V\left(t, S_{i}, B, \psi\right)$, consider the three regimes above. We assume that at the final time when election is held, $\psi=0$, the newly elected government has all boosting resources renewed from $B$ to $B_{\max }$ and thus the formulation is

$$
V\left(t, S_{i}, B, 0\right)=\sum_{j=1}^{m} P\left(W \mid S_{j}\right) Q_{i j} V\left(0, S_{j}, B_{\max }, n\right) .
$$


In the election mode, we have for $0<\psi \leq T_{L}$, where $t$ refers to discrete time,

$$
\begin{aligned}
V\left(t, S_{i}, B, \psi\right)=\max & \left\{\sum_{j=1}^{m} V\left(t+1, S_{j}, B-1, \psi-1\right) P_{i j}^{b},\right. \\
& \left.\sum_{j=1}^{m} V\left(t+1, S_{j}, B, \psi-1\right) P_{i j}\right\}+\delta t .
\end{aligned}
$$

In the election mode there are only two options, boost or not boost. The first summation in (2) is the option to boost, and the second summation is the option not to boost. In both cases, the government remains in power up to the next time step $\delta t$ with certainty. When choosing to use boosts the transition probability is $P_{i j}^{b}$ which lifts the popularity to a higher level, but the number of boost remaining decreases by one. We discuss this transition probability in the next subsection.

In the non-election mode, when $\psi>T_{L}$, the expected remaining life is

$$
\begin{aligned}
V\left(t, S_{i}, B, \psi\right)=\max & \left\{\sum_{j=1}^{m} V\left(t+1, S_{j}, B-1, T_{L}\right) P_{i j}^{b},\right. \\
& \sum_{j=1}^{m} V\left(t+1, S_{j}, B-1, \psi-1\right) P_{i j}^{b}, \\
& \sum_{j=1}^{m} V\left(t+1, S_{j}, B, T_{L}\right) P_{i j}, \\
& \left.\sum_{j=1}^{m} V\left(t+1, S_{j}, B, \psi-1\right) P_{i j}\right\}+\delta t .
\end{aligned}
$$

The above equation contains four summations which correspond to four options that can be chosen by government in the non-election mode: the first summation is when the government applies boosts and calls an election simultaneously; whereas the second one is choosing to boost but no election 
called; the third one is not to boost but to call for an election; and the last one is when opting neither to use boost nor to call an election. In all four cases, as in the election mode, the government stays in power up to the next time step $\delta t$ with certainty. In case the government calls for an election, the number $\psi$ of periods until the election will revert back to $T_{L}$ and we are now in the election mode.

We use an iterative scheme to determine the expected remaining life by starting with an initial estimate at time $t=0$ and then calculate the value at final time $V\left(t, S_{i}, B, 0\right)$ using (1). Then we use it as a boundary condition in calculating the expected remaining time in election mode in (2). Values at election mode become the boundary condition for calculating values in nonelection mode in (3). Finally, when we have calculated the value at $t=0$, we replace our initial estimate with this new value and repeat the procedure until it converges (the difference is less than some tolerance value). Algorithm 1 summarises our iterative scheme.

Algorithm 1: superscript indices represent the iteration number

1: Initiate $V^{0}$ as an estimate for $V\left(0, S_{j}, B_{\max }, n\right), j=1,2, \ldots, m$.

2: repeat

3: $\quad$ for $k=1,2,3, \ldots$

4: Calculate $V^{k}\left(t, S_{i}, B, 0\right)$ from (1) using $V^{k-1}\left(0, S_{i}, B_{\max }, n\right)$

5: $\quad$ Calculate $V^{k}\left(t, S_{i}, B, \psi\right)$ from (2) and (3)

6: $\quad$ Calculate $V^{k}\left(0, S_{i}, B, n\right)$

7: until error $=\left\|V^{k}\left(0, S_{j}, B_{\max }, n\right)-V^{k-1}\left(0, S_{j}, B_{\max }, n\right)\right\|<$ tol .

\subsection{Transition probabilities and parameter fitting}

The impact of using boosts by the government is reflected in the transition probabilities. By using boosts the government's popularity will be lifted up to a higher level and we model this using a so-called boost factor $b$. When 
there is no boost, if the poll is in state $S_{t}$ at time $t$, it will move to a state $S_{t+\delta t}$, time $\delta t$ later. In the continuous model, the state $S_{t+\delta t}$ will be normally distributed with mean $S_{t}+\alpha\left(S_{t}, t+\delta t\right)$ and variance $\sigma^{2}\left(S_{t}, t+\delta t\right)$, where $\alpha\left(S_{t}, t+\delta t\right)$ is the drift of the SDE model for the process $S_{t}$.

When using boosts, the popularity will go higher over the next time step $\delta t$ in conjunction with the drift and diffusion coefficients of the SDE. The impact of a boost is assumed to be nonlinear: it has a regressive influence in that the application of a boost when popularity is low has more impact than if the popularity is already high. Extending the model in [8], our SDE for the process is

$$
d S_{t}=-\mu\left(\frac{S_{t}}{1-S_{t}^{2}}\right) d t+\sigma d W_{t}+\beta d J,
$$

where $W_{t}$ is a Wiener process, $\mu$ and $\sigma$ are constants and $d J$ is a jump process, with value 1 only upon a boost applied by the government, and 0 otherwise. Using boost will give an additional mean of $\beta=b\left(0.5-S_{t}\right)$ in the distribution of state $S_{t+\delta t}$, however the variance remains the same. We can show using Lemma 6.3 of [6] that the process $S_{t}$ in $(4)$ remains within $(-1,1)$ given sensible assumptions on $\mu$ and $\sigma$.

Maximum likelihood estimates of parameters $\mu$ and $\sigma$ in (4) use the twoparty preferred data from Morgan Poll. The estimated value of $\mu$ and $\sigma$ are 4.12 and 0.28 respectively. The probability of winning the election given the state $S$ is also the same as in [8], which is normally distributed with mean $0.524+1.47 \mathrm{~S}$ and standard deviation of 0.00148 . This calculation is based on the 22 Federal Elections since 1949.

\section{Results}

In this section we give the numerical results of our model. The solution to the stochastic dynamic program yields the value function $V$, representing 
the expected remaining life in power, as well as the government's optimal strategy. The strategy can be expressed in terms of exercise boundaries (whether to boost, not boost, call an election or not call an election) from every state $(t, S, B, \psi)$.

\subsection{Expected remaining life}

We provide the expected remaining life, $V$, when $B_{\max }=5$ and $B_{\max }=10$ in Figures 1 and 2. The two graphs in each figure are the same but one is rotated to give a clear view. Within these figures, there are two graphs for $B=0$ and $B=B_{\max }$. From these figures we can see that at the beginning of the period the expected remaining life is near constant regardless of the level of popularity and then decreases as time elapses for low level of popularity. For higher levels of popularity there is no significant change as time elapses. When comparing two graphs within each figure, the expected remaining life is relatively shorter when there are fewer boosts remaining especially at the beginning of the period; however, at the final time the expected remaining life is the same regardless of the number of boosts left. We use boost factor $b=0.05$ to produce these figures, meaning that each boost applied will give additional $0.05(0.5-S)$ to the government's popularity. For example, if the government and the opposition are running evenly in the polls and the government applies a boost, then $S$ moves to 0.025 (that is, their two-party preferred popularity moves from $50 \%$ to $51.25 \%$ ).

\subsection{Exercise boundaries}

In this subsection there are two exercise boundaries in accordance with options available to the government, namely to use boosts and/or call an early election. We label these exercise boundaries as call exercise boundaries and boost exercise boundaries, respectively. 
(a)

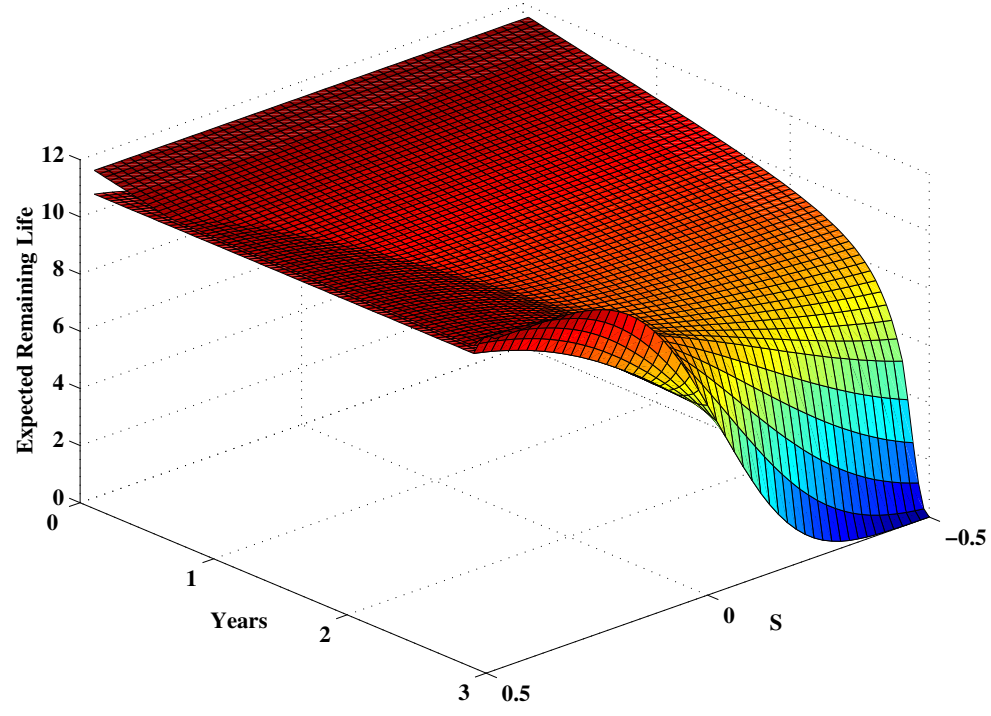

(b)

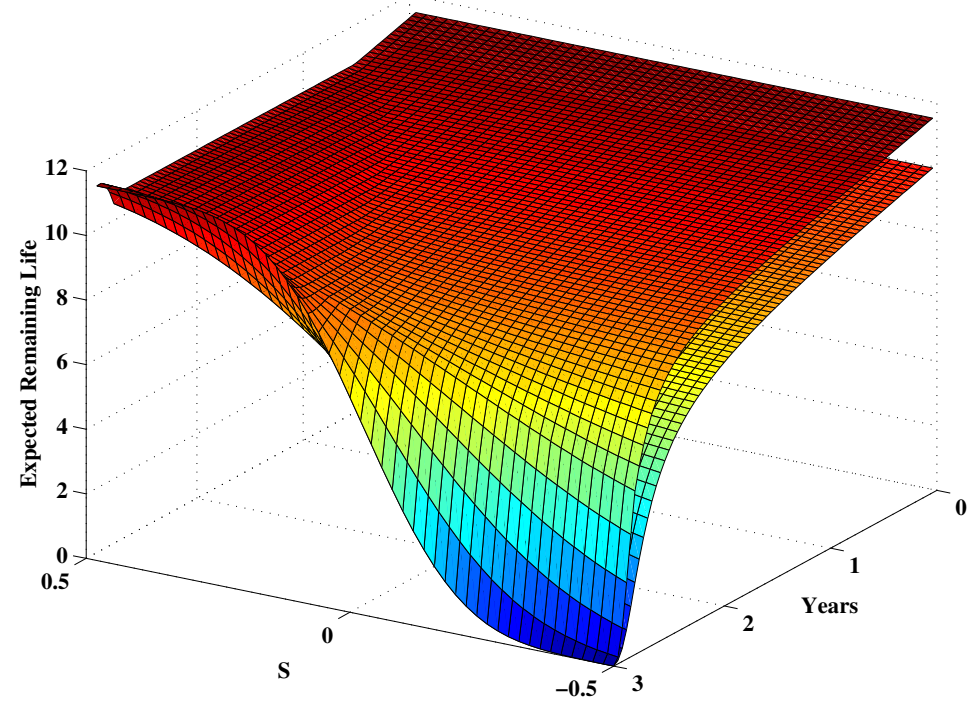

FiguRE 1: Expected remaining life with $B_{\max }=5$ 
(a)

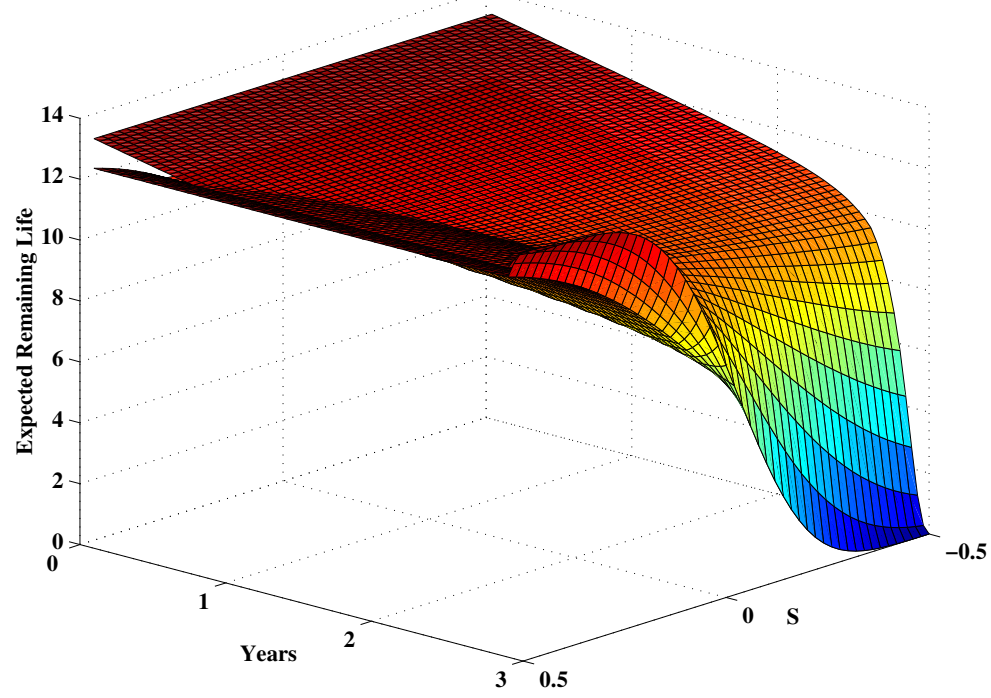

(b)

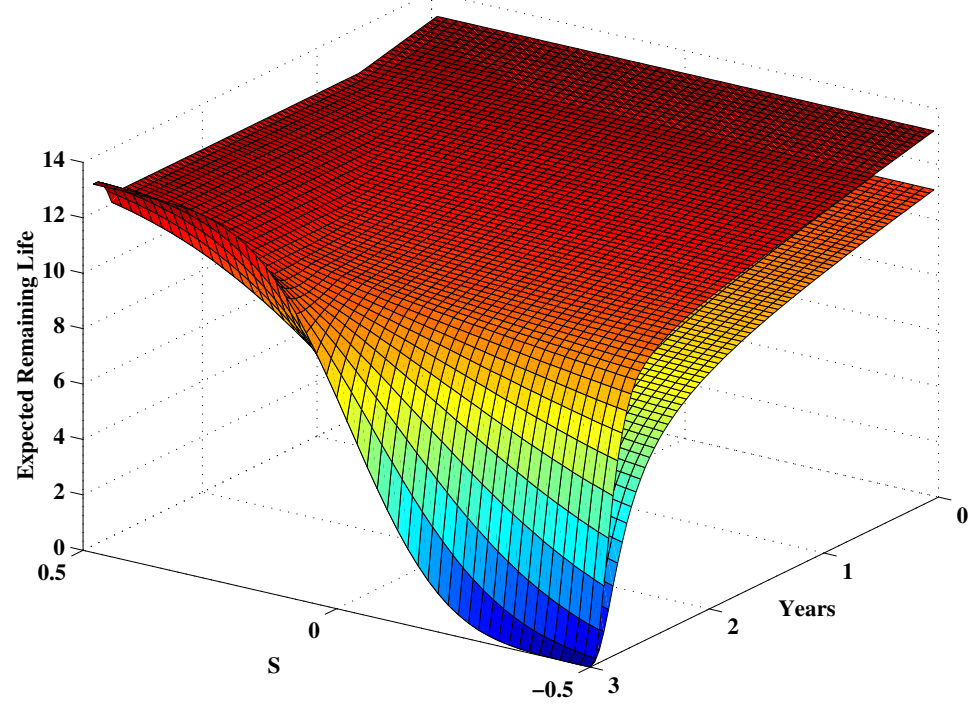

FiguRE 2: Expected remaining life with $B_{\max }=10$ 


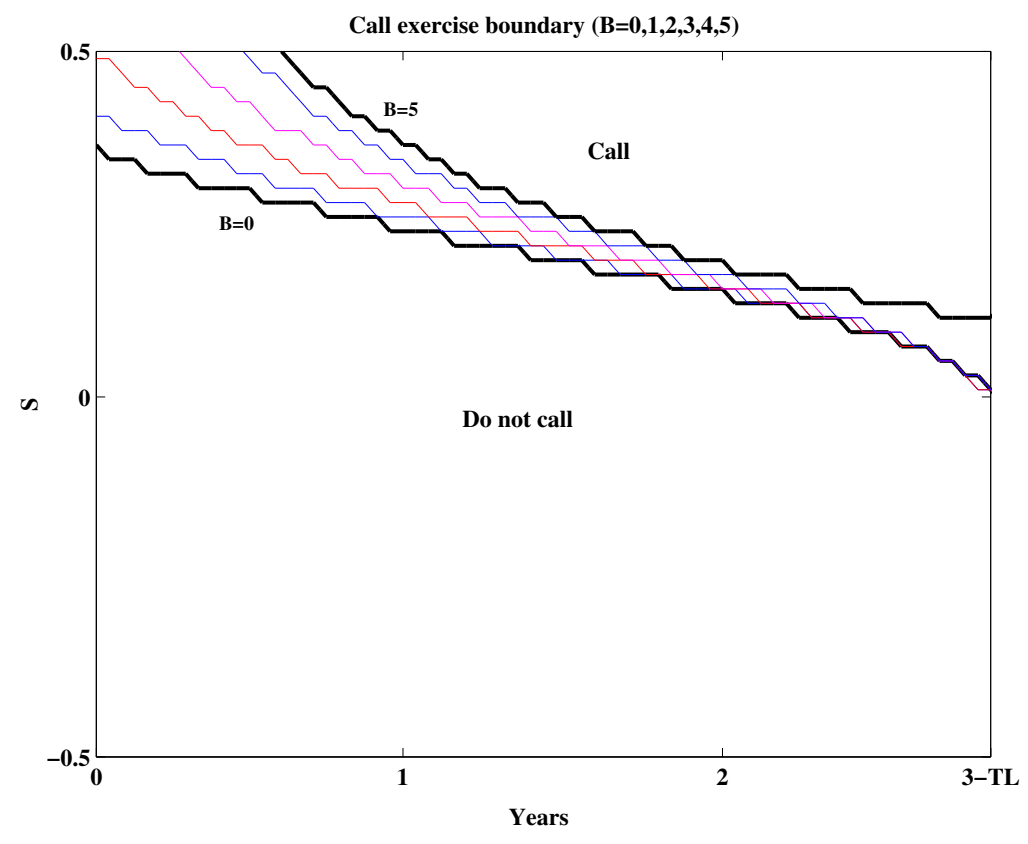

(a)

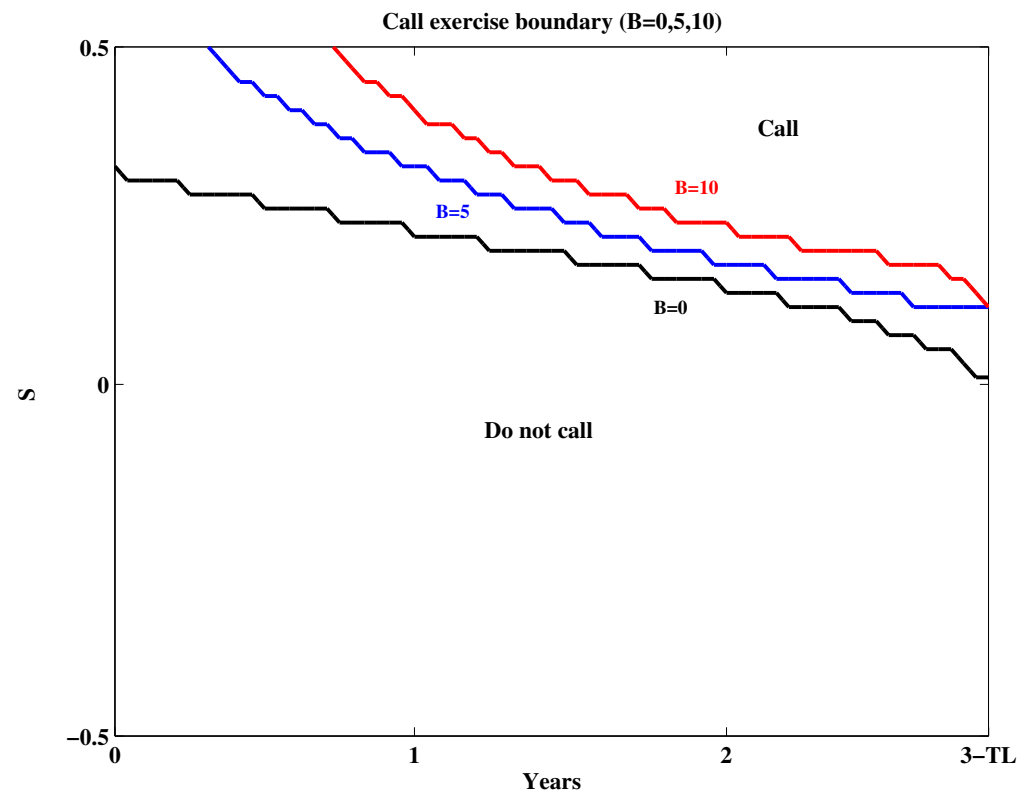

(b)

Figure 3: Call exercise boundaries with (a) $B_{\max }=5$ (b) $B_{\max }=10$ 


\subsubsection{Call exercise boundaries}

The option for calling an early election can only occur in the non-election mode and results are depicted in Figure 3(a) and 3(b) for $B_{\max }=5$ and $B_{\max }=10$ respectively. In both figures, the call exercise boundaries are monotone in time and calling an election occurs when the difference in popularity is at least zero with earlier and earlier elections needing higher and higher popularities. Having more boosts remaining lifts the call exercise boundary higher, or in other words gives a smaller exercise region for calling an early election. Consequently, when there are still boosts available, the government is unlikely to call an election voluntarily.

\subsubsection{Boost exercise boundaries}

Unlike the option of calling an early election which can only occur in the non-election mode, the option to use boosts can occur in both election and non-election modes. We provide boost exercise boundaries for $B_{\max }=5$ and $B_{\max }=10$ in Figure 4(a) and 4(b) respectively. In both figures, when $B=1,2$ and 3 , boost exercise boundaries are just vertical lines in the election mode. These mean that if there are fewer boosts remaining, they should be spent at the election mode regardless of the level of popularity. In general, for $B$ greater than 4, boost exercise boundaries are monotone in time and the government should apply boosts when the difference in popularity is at least greater than zero. Having fewer boosts makes a delicate change to the exercise region. In Figure 4(b), boost exercise boundaries are crossed over for $B=5,7$ and 10 close to the end of the period when $S$ is around zero. This means that when close to the end of the period before an election is called and $S$ is around zero and the government still has boosts to spend, they should be spent at this time and again at every time step in the non-election mode. It is also interesting to look at call and boost exercise boundaries simultaneously as per Figure 5 for $B_{\max }=10$ : see that when there are 5 or 10 boosts remaining, call and boost exercise boundaries are the same 


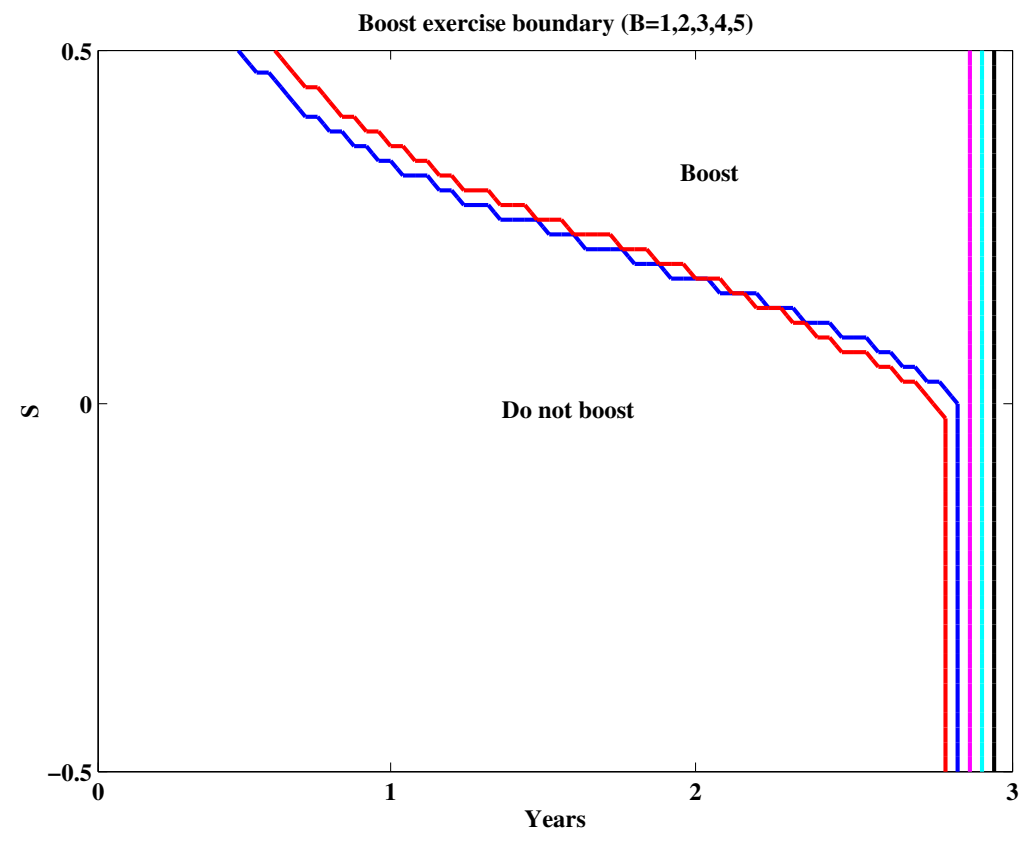

(a)

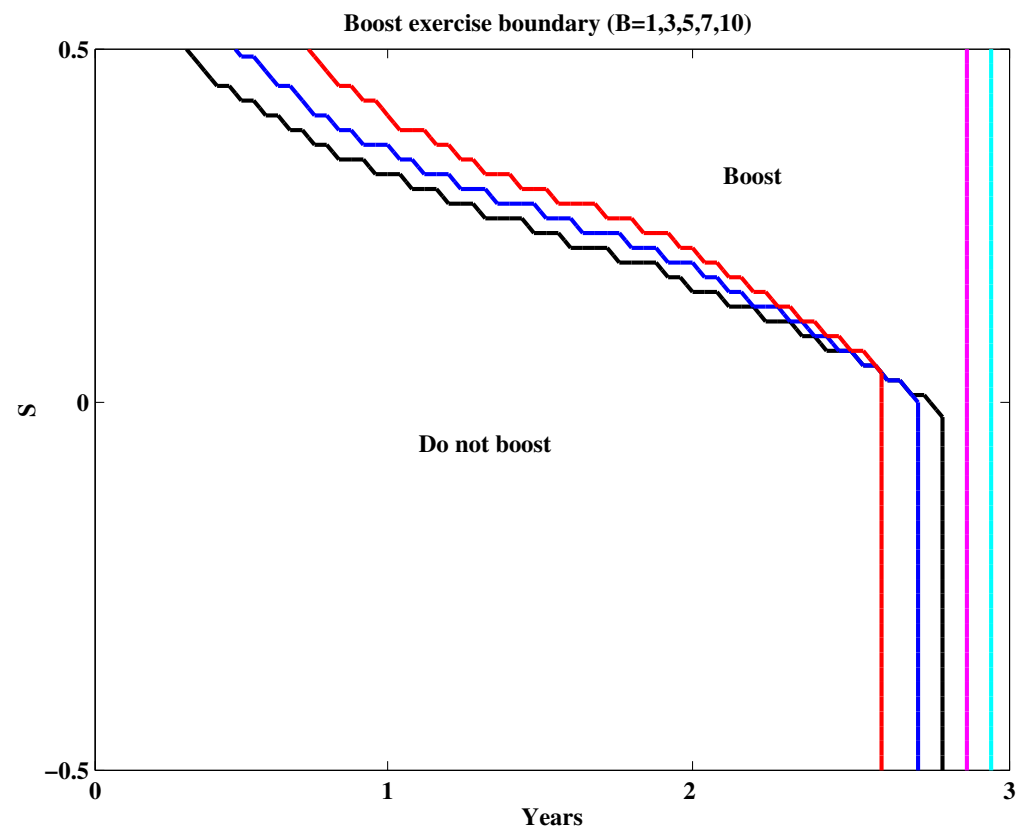

Figure 4: Boost exercise boundaries with (a) $B_{\max }=5$ (b) $B_{\max }=10$ 


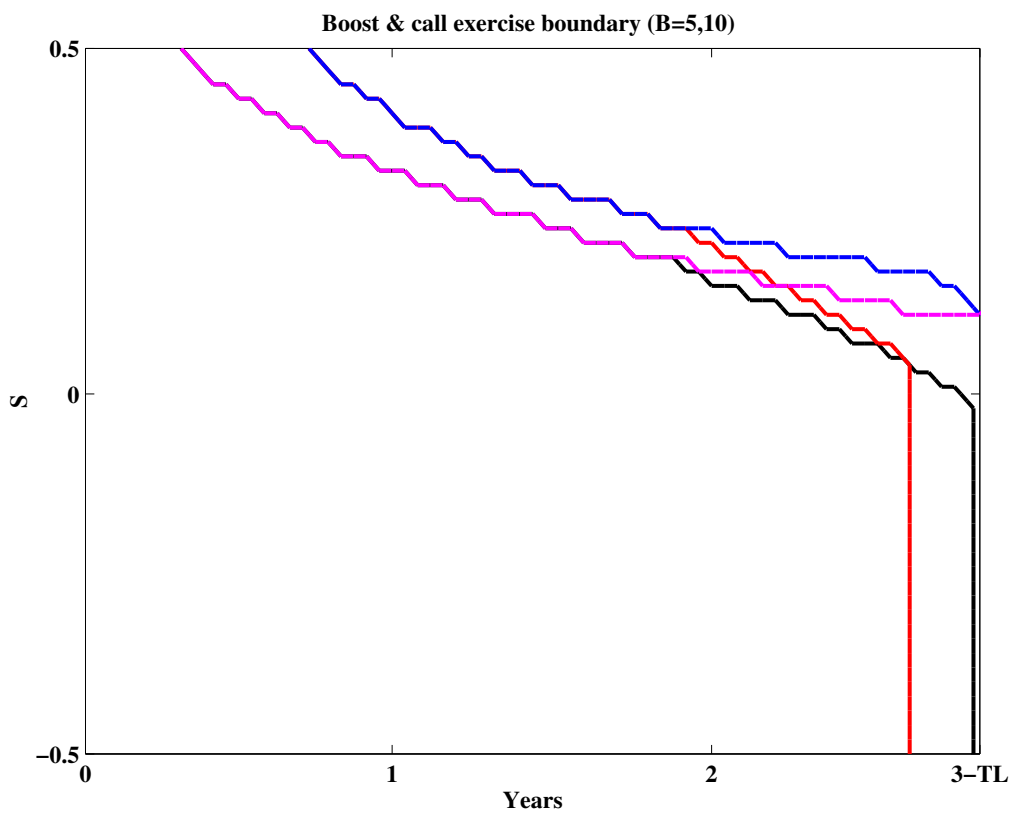

Figure 5: Call and boost exercise boundaries with $B_{\max }=10$

until in the middle of the period whereupon they diverge. This means up to the middle of the period, applying boosts and calling an election should be exercised at the same time, whereas they can be exercised separately later in the period.

\section{Extension}

In the previous model, we assumed discrete boosts of magnitude one. Here, we consider the possibility that the government can choose the size of each boost, $0 \leq \gamma \leq 1$. We assume that boost resources grow linearly with time at rate $r$ and if no boosts are used, $B_{t+\delta t}=B_{t}+r \delta t$. In this model, the government can carry its boosts across the election period into the next term. 
(a)

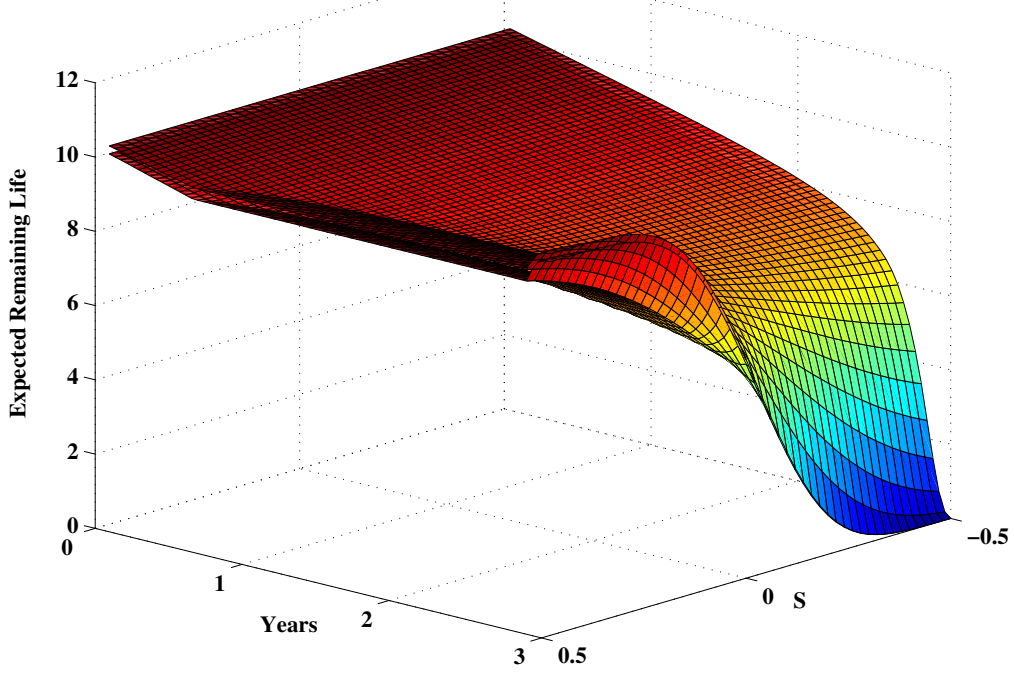

(b)

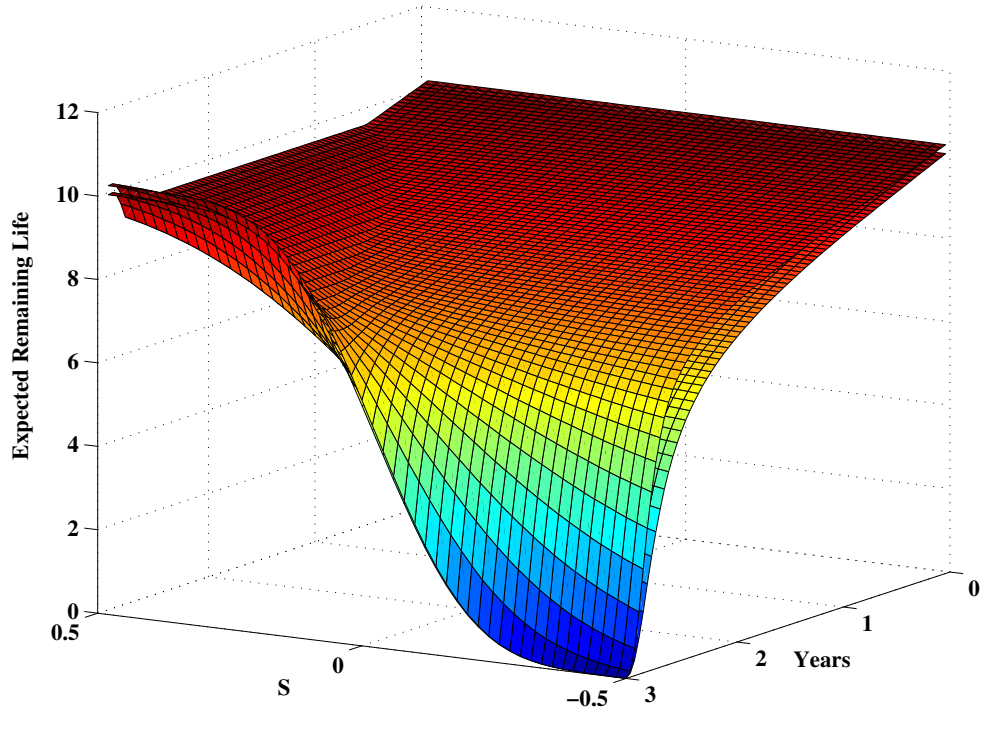

Figure 6: Expected remaining life with $B_{\max }=10$ (extension model) 
See [7] for a similar problem. Again, we divide the political time frame into three regimes. At the final time when election is held, the formulation is

$$
V\left(t, S_{i}, B_{t}, 0\right)=\sum_{j=1}^{m} P\left(W \mid S_{j}\right) Q_{i j} V\left(0, S_{j}, B_{t}, n\right) .
$$

In the election and non election period, our formulation becomes

$$
\begin{gathered}
V\left(t, S_{t}, B_{t}, \psi\right)=\max _{0 \leq \gamma \leq 1}\left\{\sum_{j=1}^{m} V\left(t+1, S_{j}, B_{t}-\gamma+r \delta t, \psi-1\right) P_{i j}^{\gamma}\right\}+\delta t(6) \\
V\left(t, S_{t}, B_{t}, \psi\right)=\max \left\{\max _{0 \leq \gamma \leq 1} \sum_{j=1}^{m} V\left(t+1, S_{j}, B_{t}-\gamma+r \delta t, k \delta t\right) P_{i j}^{\gamma},\right. \\
\left.\max _{0 \leq \gamma \leq 1} \sum_{j=1}^{m} V\left(t+1, S_{j}, B_{t}-\gamma+r \delta t, \psi-1\right) P_{i j}^{\gamma}\right\} \\
+\delta t,
\end{gathered}
$$

where $P_{i j}^{\gamma}=(1-\gamma) P_{i j}+\gamma P_{i j}^{b}$. Recall that in the election period, the government can only use boosts since election has already been called. However, in (6), the government can choose the size of boost that maximizes the expected remaining life in power. Also, in the non-election mode the government has options to call and/or use boosts as formulated in (7) and then the expected remaining life in power is the maximum between calling or not calling an election with optimum size of boost in each choice. Results are given in Figure 6 and 7 in terms of expected remaining life in government, call exercise boundaries and boost intensity, all with $B_{\max }=10$. Within Figure 5(b), there are two graphs of the expected remaining life, for $B=0$ and $B=B_{\max }$. Call exercise boundaries in Figure 7(a) are given for various values of the number of boosts remaining, $B=2,5,8,10$. The boost intensity in Figure 7(b) indicates the size of each boost that the government should apply at any time step at any level of popularity. The trend of the expected remaining life and call exercise boundaries in Figure 5(b) and 7(a) 
is similar to the previous model. The expected remaining life is almost constant at the beginning of the period regardless of the level of popularity and monotonically decreasing for low level of popularity as time elapsed. Call exercise boundaries monotonically decrease in time and having more boosts remaining narrows the exercise region, meaning that an early election is unlikely to be called. However, in the earlier life of the government there is no substantial difference in the call exercise boundaries for different values of the remaining boosts. One difference in our results from the previous model is the boost intensity. In the previous model we provide the boost exercise boundaries, since the size of boost is equal to unity. Here, since the government can choose the size of its boost, $0 \leq \gamma \leq 1$, to maximize its expected remaining life, the decision to boost is given in a matrix form. In each level of popularity and at any time step, the boost intensity gives the optimal size of the boost that the government should apply.

\section{Conclusions and further research}

We have given the expected remaining life in government and exercise boundaries for our model by assuming that the government can apply boosts at any time step at any level of popularity given a certain amount of boost available at the beginning of period. The expected remaining life is longer when there are more boosts available, especially during the early life of the government. However, at the final time the expected remaining life remains the same regardless of the number of boosts left at that time.

For exercise boundaries, we differentiate between call and boost exercise boundaries which both can only occur in the non-election mode. Boost exercise boundaries themselves can also occur in the election mode. These exercise boundaries are monotone in time in the non-election mode and as the number of boosts increase, the exercise boundary is lifted, giving a smaller exercise region. In terms of call exercise boundaries, this means that the 


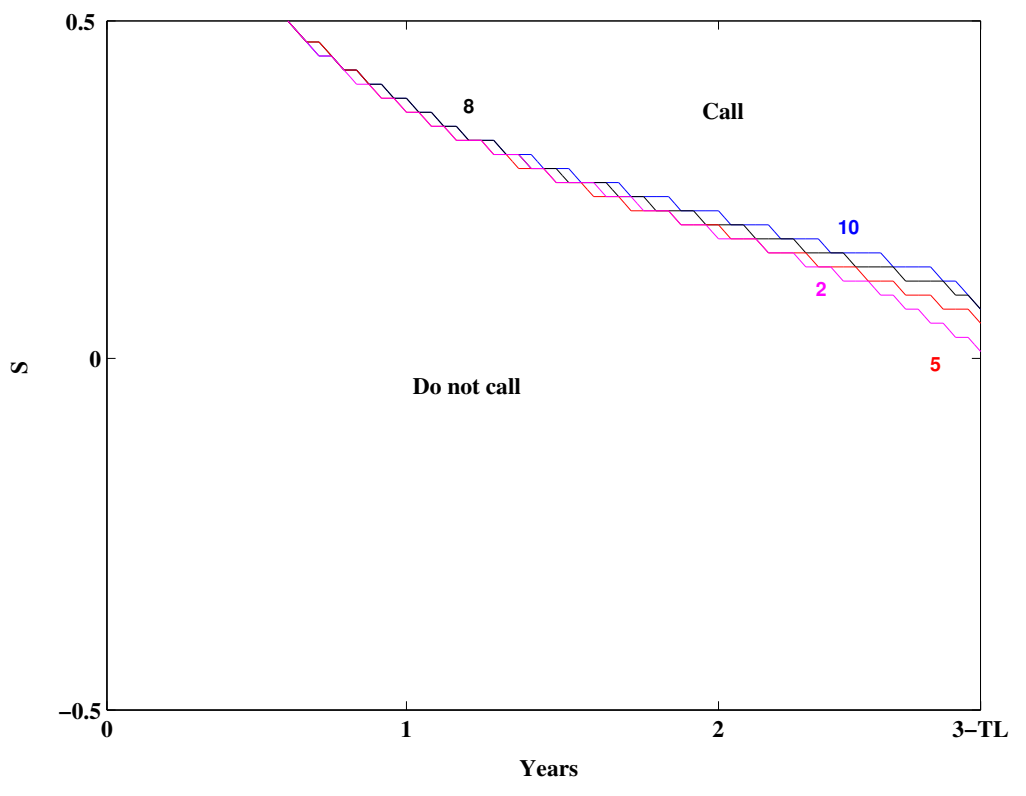

(a)

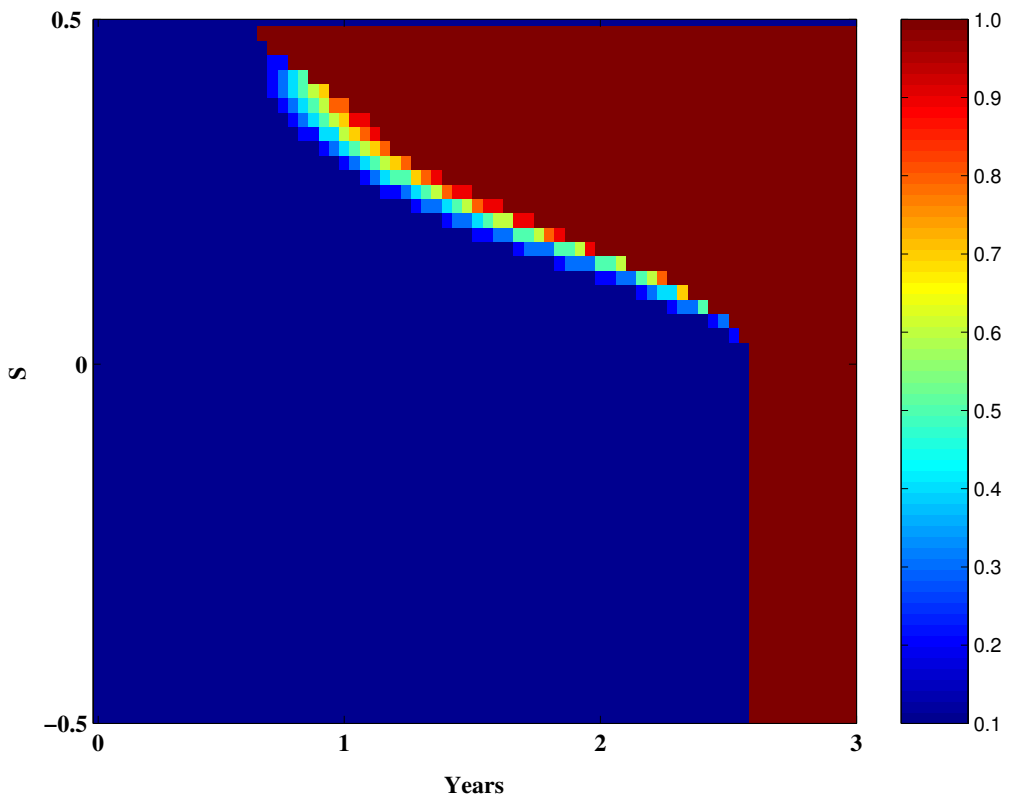

(b)

Figure 7: (a) call exercise boundaries with $B_{\max }=10$ (b) boost intensity with $B_{\max }=10$ 
government is unlikely to call an early election if it still has enough boosts to spend. The same condition applies for the boost exercise boundary. When there are still boosts available, as in Figure 4(a), for $B=2,3$ and 4, they should be spent at every time step during the election mode regardless of the level of popularity.

We also gave an extension to our model by considering the possibility for the government to choose the optimum size of its boosts that maximizes its expected remaining life in power. Our boost intensity gives the size of boosts the government should apply at any time step at any level of popularity.

We assume that only the government can apply boosts by introducing some policies or economic actions. However, it would be interesting to consider an extension in which the opposition can apply negative boosts that pull down the government's popularity and the government can only call an early election. Another possibility is when both the government and the opposition can apply boosts to raise their popularity or to pull down their opponent's popularity — this will lead us to a game theory problem.

Acknowledgment: We are grateful to the reviewers for their helpful suggestions. The support of AusAid and the Australian Research Council Centre of Excellence for Mathematics and Statistics of Complex Systems for the first author are gratefully acknowledged.

\section{References}

[1] Balke, N. S. The Rational timing of Parliamentary Elections. Public Choice, 65, 201-216, 1990. C766 
[2] Dahlberg, M. \& Johansson, E. On the Vote-Purchasing Behavior of Incumbent Governments. American Political Science Review, 96(1), 27-40, 2003. C766

[3] The Department of Parliamentary Library. Electoral Systems Research Paper No. 1989-90. Canberra: Author, 1999. C766

[4] Grant, R. Federal government advertising. Department of Parliamentary Services Research Note 2003-04 No. 62, 21 June 2004. C766

[5] Jérôme, B., Jérôme, V. \& Lewis-Beck, M. S. Polls fail in France: forecast of the 1997 legislative election. International Journal of Forecasting, 15(2), 163-174, 1999.

http://dx.doi.org/10.1016/S0169-2070(98)00065-X C766

[6] Karlin, S. \& Taylor, H. M. A Second Course In Stochastic Processes. New York: Academic Press, 1981. C772

[7] Kayser, M. A. Who Surfs, Who Manipulates? The Determinants of Opportunistic Election Timing and Electorally Motivated Economic Intervention. American Political Science Review, 99(1), 1-11, 2005. C781

[8] Lesmono, D., Tonkes, E. J. \& Burrage, K. An early political election problem. ANZIAM J., 45(E), C16-C33, 2003. [Online] http://anziamj . austms.org.au/V45/CTAC2003/Lesm. C766, C767, C772 